\title{
BİR HALK HEKIMLİĞİ UYGULAMASI ÖRNEĞİ: “GELİNCİK KESME”
}

\author{
AN EXAMPLE OF FOLK MEDICINE PRACTICE: “GELINCIIK KESME”
}

\section{Recep DEMIR*}

ÖZ: Bu çalışma halk hekimliği ve bir halk hekimliği uygulaması örneği olarak Düzce'nin Akçakoca ilçesine bağlı Balatlı Köyü'nde uygulanan "gelincik kesme" tedavisi ve bu tedavide yer alan halkbilimi açısından önem atfeden unsurların değerlendirilmesini içermektedir. Binlerce yıllık deneyimlerle oluşmuș halk hekimliği yöntemleri ve inanmaları halkbilimi çalışmalarında büyük yer tutmaktadır. İnsanoğlu yaratılışından itibaren hastalıklara yakalanmış, bu hastalıkları çeşitli yollarla tedavi edip edindiği birikimleri sonraki nesillere aktararak günümüze kadar sürekli artarak ulaşmış halk hekimliği bilgisine sahip olmuştur. $\mathrm{Bu}$ bilgilerin oluşumunda bitkilerin iyileștirici yönlerinin ve etkilerinin zamanla öğrenilmesi, Şamanizm'e ait inançların sonraki dönemlerde kullanılmaya devam edilmesi, İslamiyet'in kabulünden sonra İslami unsurların da tedavilerde yer alması etkili olmuştur. Halk arasında bu bilgilerin uygulanıșı konusunda uzmanlașmıș ve belli bir düzeyde saygınlığa sahip, "ocaklı" olarak adlandırılan şifacılar vardır. Çeşitli hastalıkların tedavisinde uzmanlaşan şifacılar ya kısıtlı olanaklar ya utanma gibi sebeplerden ötürü halkın modern tıbbın imkânlarından yararlanma şansı olmadığında ya da modern tıbbın ilgilenmediği metafizik konularda hastalıklara karşı mücadele etmektedirler.

Halk inançlarında kendini değişik biçimlerde gösteren ve oldukça yaygın olan nazarın doğurduğuna inanılan sonuçlarının modern tıp tarafından sağaltılamadığına dair kabuller bulunmaktadır. Saha çalıșmasının yapıldığı çevrede nazar sonucu vücudunda yara, çıban, kızarma, șişlik vb. çıkan kadınların "gelincik" olduğuna inanılır ve nazarın kișiden uzaklaștırılması için "gelinciğin kesilmesi" gerektiği inancı hâkimdir. "Gelincik kesme" işlemi sırasında Türk mitolojisi ve modern Türk folkloruyla ilgili halkbilimi açısından değer taşıyan: tedaviyi gerçekleștiren kişinin ustasından el almış bir "ocaklı" olması, hastalığın sebebinin nazar olması, iyileștirme sırasında demirin gücünden yararlanılması, "sol" üzerinde olușan tabunun bu uygulamada da görülmesi, Türklerdeki önemli sayılardan biri olan 3 sayısının birçok yerde tekrar edilmesi gibi unsurlar bulunmaktadır.

Anahtar Kelimeler: Halk hekimliği, gelincik kesme, tedavi, kadın şifacılar, nazar.

ABSTRACT: This study includes folk medicine and as an example of folk medicine practice "gelincik kesme treatment" which is applied in Balatllı Village in Akçakoca-Düzce and also evaluation of elements that attach importance to folklore in this treatment. Folk medicine methods and beliefs formed with thousands of years of experience have a great place in folklore studies. Mankind has been suffering from illness since its creation, he has acquired knowledge of folk medicine that has been increasing everyday by transferring his knowledge he has defeated in various ways to the next generations. There are factors such as the learning of the healing powers of the plants in time, the continued use of the beliefs of Shamanism which is the old belief of the Turks, the acceptance of Islam and the inclusion of Islamic elements in the treatment in the formation of this information. There are healers who are called "ocaklı" specializing in the

\footnotetext{
* Arş. Gör. - Ondokuz Mayıs Üniversitesi Fen-Edebiyatı Fakültesi Türk Dili ve Edebiyatı Bölümü / Samsun - recepdemir@omu.edu.tr (ORCID ID: 0000-0002-7021-128X) 
application of this information to the public and who have a certain level of prestige. Healers specializing in the treatment of various diseases, have fought against diseases when people have no chance to benefit from the opportunities of modern medicine due to reasons such as limited opportunities, shame or in the metaphysical issues that modern medicine is not interested in. Evil eye which is widely known among the people and has many beliefs on it is one of the diseases which are not treated by the doctors. It is believed that the women who have wounds, boils, flushing, swelling in their body because of evil eye are "gelincik" and the belief which is necessity of "gelincik kesme" to cure evil eye is widely known in the surrounding area. There are some elements in the process of "gelincik kesme" treatment which have value for Turkish mythology and modern Turkish folklore, such as person performing the treatment is called "ocaklı" authorized from her master, evil eye is the cause of the illness, the usage of power of iron during the treatment, The taboo formed on the "left" is also seen in this practice and the repetition of number 3 which is one of the important numbers in the Turks.

Keywords: Folk medicine, gelincik kesme, treatment, women healers, evil eye.

\section{Giriş}

Hastalık, kişinin vücudunda veya ruhunda meydana gelen normal dışı durumları ifade eden bir olgudur. Bu olgu bazen vücuttaki bir eksiklik, yetersizlik, fonksiyon bozukluğu, ağrı-sızı olabilirken bazen de halk hikâyelerinde, masallarda veya destanlarda en çok karşılaşılan motiflerden biri olan çocuksuzluk, nazar veya ruhsal bozukluk olabilir. Hastalık kavramının farklı tanımları bulunmakla birlikte Pertev Naili Boratav'ın ifadesiyle hastalık yalnızca kişinin sağlık durumundaki aksaklıkları değil, kısırlıktan nazar değmesine, insanlardan gelen kötü etkilere ve tabiatüstü varlıkların sebep olabilecekleri sakatlıklara kadar türlü bozuklukları içerir (Boratav, 2015: 140).

Hastalık âmilleri insanın ortaya çıkışından önce de mevcuttu. Günümüze ulaşan fosiller, hastalıkların milyonlarca yıl değișmediğini göstermektedir (Bayat, 2016: 32). Hastalığa yakalanan insan bu durumdan kurtulmak için çareler, yollar aramıştır. Bu çabalar kendini bazen büyü, bazen dua, bazen de iksir kullanımı şeklinde göstermiştir. İnsanoğlu gün geçtikçe hangi yöntemlerin tedavilerde kullanılıp tedaviye katkı sağladığını, hangi yöntemlerin tedaviye etki etmediğini veya olumsuz sonuçlar doğurduğunu deneyerek öğrenmiş ve bu birikimi nesilden nesile aktarmıştır. Deneme yanılma yoluyla edinilen bilgilerin artmasıyla büyü ikinci plana atılmış ve modern tıbbın doğuşuna zemin hazırlanmış, büyü ile tıp iki ayrı tedavi yolu olarak varlıklarını sürdüre gelmiştir (Doğan, 2011: 121). Malinowski bilim ve büyü ayrımını "Akılcı bilimin özü ile büyü öğretisinin özü farklı geleneklerde, farklı toplumsal çevrelerde ve farklı türden etkinliklerde cisimlenmişlerdir. Ve bütün bu farklar ilkellerce iyi bilinir. Biri maddi alanı kurar; diğeri ise, geleneklerle, mitlerle ve tabularla çevrili olarak manevi alanın bir yarısını oluşturur" şeklinde açıklamıştır (Malinowski, 1990: 76).

Boratav'ın hastalık tanımlamasında (2015:140) yer alan nazar değmesi ve tabiat dışı varlıklardan kaynaklanan bozukluklar gibi metafizik 
veya soyut durumlar karşısında modern tıp belli bir tedavi yöntemi uygulamamaktadır. Böyle durumlarla karşılaşıldığında hasta olan kişi halk arasında "kocakarı ilacı/tedavisi" olarak bilinen, modern toplum tarafindan "batıl inanç" olarak görülen yöntemler kullanan halk hekimlerine (ocaklılara) başvurur. Fakat Doğan'a göre, halk hekimliği uygulamalarının hepsine batıl inanç demek yanlıştır. Batıl inanç ve dinî/büyüsel uygulamalar haricindeki halk hekimliği uygulamalarının günümüzde alternatif tıp alanında kullanılıp olumlu sonuçlar verdiği bilinmektedir (Doğan, 2011: 123).

Modern tıbbın doğuşunda ve gelişmesinde büyücülerin katkısı büyüktür. Büyücülerin kullandığı yöntemler zamanla tecrübenin yardımıyla yorumlanarak hekimler tarafından kullanılmıştır. Bugün birbirine zıt olan büyü ve tıbbın, tarihin derinliklerine gidildikçe yakınlaştıkları hatta modern hekimin atasının büyücüler olduğu söylenebilir (Ronan, 1983: 6). Modern tıbbın günümüzde tedavi için kullandığı birçok ilacın hazırlanmasında ve ilaçların özünü oluşturan etkin maddelerin belirlenmesinde halk hekimliği uygulamaları yer almaktadır. Hufford'un "Halk Hekimleri" adlı makalesinde bu konuya örnek olarak "yüksük otu" nun kullanımı verilmiștir. 18. yüzyılda henüz İngiltere'de kalp hastalığının tedavisinde bu ot kullanılmazken çok daha öncesinde Avrupalı ve Amerikalı/Kızılderili otacıların bu otu kullandığı belirtilmiştir. Ancak bu otun ilaçlarda kullanılmaya başlanması resmi olarak William Withering'e mâl edilmiştir (Hufford, 2009: 385).

Anadolu'da halk hekimliği uygulamalarının kökenlerinin Türklerin eski inancı olan Şamanizm'e ait bazı ritüellere ve inançlara dayandığı, bu uygulamaların İslam dininin kabulü ile birlikte bazı değişikliklere uğramakla beraber temelde eski Türk inancının unsurlarını barındırdığı bilinmektedir. Anadolu'da halk hekimliği uygulamalarında Acıpayamlı'nın "Anadolu halk hekimliğinin temelinde büyüsel ilke ve motiflerin varlı̆g görülmektedir. Çünkü Anadolu folklorunun temelinde Şamanizm'in uygulama, motif ve kalıntılarına rastlanmaktadır" (Acıpayamlı'dan aktaran Şar, 2005: 132) şeklindeki ifadeleri bu durumu destekler niteliktedir.

Eski Türk inancı Şamanizm'de, hastalıklara sebep olan etkenler kötü ruhlar ve iyelerdir. Şamanist inanca göre insanları koruyan, sağlıklı yaşamalarını sağlayan iyi ruhların yanı sıra insanlara kızdıklarında veya onlardan rahatsız olduklarında hastalıklar gönderen kötü ruhlar da vardır. Örneğin; kötü ruhların başkanı olarak bilinen ve yer yaratılırken ilk kez fenalık düşünmesinden dolayı yer altında yaşamaya mahkûm edilen Erlik; insanlara her türlü kötülükleri yaparak, insanlara ve hayvanlara türlü türlü hastalıkları göndererek onlardan kurban beklemektedir (İnan, 2015: 39). Bayat da mitolojik verilerden hareketle insanın hasta olmasını, asabiyetini, halsizliğini, ruh düşkünlügünü vs. yalnızca insanlarda bulunan "kut"un kötü ruhlar tarafından çalınmasından veya yenilmesinden kaynaklandığını söylemektedir (Bayat, 2010: 108). Böylesi bir inanç ortamında, somut sebeplere bağlı hastalıklar da olsa, soyut, manevi sebeplere bağlı hastalıklar 
da olsa tüm hastalıkların arkasında iyelerin ve kötü ruhların bulunduğu kabul edilmektedir (Sever, 2015: 185). Kötü iye ve ruhlar insanlara ve hatta insanlığa türlü zararlar vermeyi amaçlamaktadırlar. Örneğin Çelik, Türk kültüründe yaygın olarak tanınan demonlardan biri olan Al Karısı'nın doğum esnasında ortaya çıkmasını; soyun, akrabalık ilişkilerinin ve kültürel örüntünün sürmesini engelleyerek tüm uygarlığı yok etmek istemesine bağlamaktadır (Çelik, 2018: 78). Hastalıkların kötü iye ve ruhlardan ortaya çıktığını ileri süren bu inanç, İslamiyet sonrasında "Derdi veren Allah dermanını da verir." sözünde de varlığını sürdürmeye devam etmiştir. İslamiyet öncesindeki inançtan farkı ise kötü ruhların ve iyelerin yerini Allah inancının almıș olmasıdır.

Eski Türk inancında hastalıkların sebebinin manevi güçler (ruhlar, iyeler, tanrılar vs.) olduğu düşünüldüğünden, insanlar ve manevi güçler arasında bağlantı kuran, iki taraf arasındaki taleplerin karşılanmasında yol gösterici olan ve kamlık denilen bu müesseseye ihtiyaç duyulmuştur. Gerçek bir kam, ruhların gücünü kullanır, onları kısmen kontrolde tutar, ruhların istek ve arzularını bilir ve en önemlisi ruhlar tarafından yol gösterilmiş ve yönlendirilmiş olur (Bayat, 2010: 16). Kamın birçok görevinin yanında en önemlilerinden biri de çevresindeki halkın ve hayvanların sağlıklı bir şekilde varlığını sürdürmesi amacıyla ruhlarla iletişim halinde olmasıdır. Bu amaç çerçevesinde hasta olan kişiyi sağlığına kavuşturmak için ayinler düzenler, ruhlarla pazarlıklar eder ve onlara hastanın kurtulmasını sağlamak maksatlı çeşitli kurbanlar sunar. Eski Türklerde kadın ve erkek arasında toplumsal sınıf ayrımı olmadığından kamlıkta da herhangi bir ayrım bulunmamaktadır. Kadın veya erkek kamın tedavide birbirine karşı bir üstünlüğü olmadığı gibi, ancak bazı özel durumlarda kadın kamların belli hastalıklar konusunda ihtisaslaştığı bilinmektedir.

Tedavi ediciler, halk hekimliği uygulamalarının ilk izlerinin sergilendiği törenlerden günümüze kadar yalnızca büyüsel/dinî uygulamaları değil; ilaçları, bitkileri ve bazı hayvansal ürünleri de ruhu ve bedeni iyileştirmek için kullanmışlardır. Çeşitli sebeplerle hastalığa tutulanlar doktora gidemedikleri takdirde, bitkilerden ilaçlar yapmak, yatırları ziyaret etmek, muska yazdırmak veya bir ocaklıya başvurmak gibi tedavi usullerine müracaat ederler (Duvarcl, 1990: 34). "Ocak" veya eşanlamlı olarak kullanılan "ocaklı" terimi, halk arasında çeşitli hastalıkların tedavisinde uzmanlaşmış kişilere verilen isimdir. Ocaklı olmak hususunda herhangi bir cinsiyet ayrımı yapılmasa da bazı hastalıkların tedavisinde yalnızca kadınlar bilgi sahibidir. Kadını ilk hekim olarak kabul eden Bayat bu iddiasını ileri sürerken ilkel toplumlarda çocuğunu tedavi edenin, yaşlılara bakanın, kocasını iyileștirenin hep kadın olduğunu ve bu kadının şaman olsa da olmasa da ilk tabip, ilk iyileştirici kabul edilmesi gerektiğini belirtmiştir (Bayat, 2015: 110).

Düzce İli'nin Akçakoca İlçesi'nde yer alan Balatlı Köyü'nde karşılaştığımız "Gelincik Kesme” pratiğine dikkat çekilecek olan çalışmada 
adı geçen "Gelincik" hastalığı ve "Gelincik Kesme" olarak bilinen bu hastalığın tedavisi de yalnızca kadınlar tarafından gerçekleștirilen bir halk hekimliği uygulamasıdır. Gelincik kesme uygulama safhaları, inanç boyutu ve geleneksel yönleri değerlendirilecek ve çözümlenecektir. Bu amaçla, Balatlı Köyü'nde gözlem ve mülakat tekniklerine dayalı bir saha çalışması yapılmıştır. Çalışma için tercih edilen köyün bizzat makale yazarının doğup büyüdüğü köy olması, kaynak kişiye ulaşmada ve iletişim kurmada kolaylık sağlamıştır. Kaynak kişi, 50’li yaşlarda iken köyde daha önce bu hastalığı tedavi eden kişiden "el aldığı"nı ve kendisinin tedaviyi bu yetkilendirme sayesinde yapabildiğini söylemiştir.

\section{Halk Hekimliğinde Gelincik Kesme Tedavisi}

Halk arasında çok bilinen "Nazar insanı mezara, hayvanı kazana götürür." atasözünde ifade edilen, nazarın ölüme dahi yol açabilecek kadar ciddi bir hastalık olduğu kanısı yöre insanı (Düzce ili ve çevresi) tarafından genel kabul gören bir inanıştır. Nazar kişi üzerinde ruhsal ve fiziksel olarak etkilerini göstermektedir. Halk arasında kendisine nazar değdiğine inanılan kişide göz değmesinden kaynaklandığına inanılan kişinin vücudunda meydana gelen ak veya kırmızı çıban, şişlik, morluk, incinme gibi fiziksel olarak gözlemlenebilen durumların tedavisi amacıyla "gelincik kesme" uygulanır. Belirtilerden herhangi biriyle karşılaşan genellikle kadınlar nadiren erkekler hastalıklarının tedavisi amacıyla "ocaklı" olarak kabul edebileceğimiz halk hekimine müracaat etmektedirler. Edinilen bilgilere göre, kişi yukarıdaki belirtileri gösteriyorsa gelincik olmuştur ve doktora gitmesi kişiyi iyileştirmeyecektir. Hastalığın tedavisi gelinciğin "ocaklı" tarafından kesilmesiyle gerçekleşecektir.

Hastalığın tedavi süreci şu şekilde gerçekleşmektedir: Hasta, sol ayağının üzerine oturur. Sağ ayağı ise kıbleye uzatılmış, çorapsız ve yalın vaziyette olmalıdır. Ocaklının tam karşısında bulunur ve ocaklıya "Niye geldin?" diye sorar. Ocaklının "Ak gelinciklerini, kırmızı gelinciklerini, köstebeklerini kesmeye geldim." cevabı üzerine hasta "Kes gitsin." der. Bu konuşma hasta ve ocaklı arasında üç kez tekrarlanır. Sonra ocaklı içinden üç defa Arap alfabesini ardından üç defa Tebbet Sûresi ve üç defa İhlâs Sûresi'ni okur. Okurken hastanın başından ayaklarına kadar vücudunun çevresinde, özellikle fiziksel belirtinin bulunduğu yere temas ettirilerek demir bıçak gezdirir. Bıçağın gelinciği keseceğine ve nazarı hastanın vücudundan uzaklaştıracağına inanılmaktadır. Dua okuma evresi bittikten sonra ocaklı elinden bıçağı bırakır ve hastanın başından ayağına kadar üç kez ellerini gezdirir. Bu esnada her gezdirme sırasında "El benim elim değil Fatma Anamızın elidir, şifa ondandır." demektedir. Bu işlemin ardından ocaklı "Kestim gitti" dediğinde gelincik kesme tedavisi tamamlanmış olur. Ancak bundan sonra hasta çevresindeki kimseye bakmadan dışarıya yani dağa-taşa bakmak zorundadır; hasta birine baktığı takdirde, "gelinciğin" baktığı kişiye geçeceğine ve bakılan kişinin "gelincik" olacağına inanılmaktadır. Ocaklı 
tedaviyi üç gün peş peşe tekrarlar ve üç günün sonunda hasta sağlığına kavuşur.

Ocaklı bu yöntemle birçok hastayı sağlığına kavuşturduğunu belirtmiştir. Tedavinin adında "kesme" geçmesine rağmen tedavi sırasında hastanın herhangi bir yeri kesilmeyip bıçakla yalnızca simgesel olarak kesme işlemi yapılmaktadır. Tedavinin geçmişteki ile günümüzdeki uygulanış şekli arasında bir fark olmayıp, ocaklının ustasından gördügü ve öğrendiği şekilde tedaviyi gerçekleştirdiği; ayrıca kendisinden sonra el vereceği çırağı henüz bulamadığı da edinilen bilgiler arasındadır (KK-1). Hastalığın tedavisinde Ankara'nın Polatlı ilçesinde farklı bir yol izlendiği görülmüștür. Halk hekimi adı geçen ilçede Felak ve Nas Surelerini okuyarak hastaya bir haftalık perhiz vermiştir (Başaran ve Solmaz, 2014: 62). Anadolu'nun farklı coğrafyalarında uygulama farklılıkları görülse de halkın "gelincik" hastalığı için ocaklılara başvurma geleneği değişmemektedir.

Bir derleme çalışmasında dikkat edilmesi gereken birçok etken bulunmaktadır. Bunların en önemlilerinden biri kaynak kişinin seçimidir. Ekici'ye göre, bazı kaynak kişiler bazı halk bilgisi ürünlerinin yaratım ve aktarımında ustalaşmış hatta bu işi meslek olarak edinmiş olabilirler (Ekici, 2015: 30). Tedaviyi gerçekleştiren kaynak kişi aynı zamanda ocaklının herhangi bir tıbbî eğitim almamış olması ve buna ek olarak eğitim hayatı ilkokul 2. sınıftan itibaren bitmiş olmasına rağmen halk arasında "gelincik" olarak bilinen hastalık söz konusu olduğunda doktordan daha fazla itibar görmesi halkbilimi açısından önemlidir. Ayrıca Âşık Tarzı Halk Edebiyatının icracıları olan âşıkların geleneği öğrenme ve öğretme sürecinde karşımıza çıkan ustadan "el alma" ve çırağa "el verme" kavramları, çalışmamızdaki ocaklının tedaviyi öğrenme sürecinde gerçekleşmiş olup öğretme sürecinde de gerçekleşeceği anlaşılmaktadır.

"Gelincik kesme" uygulamasında yer alan folklorik unsurlardan biri hastalığın oluşabilmesi için kişiye değmesi gereken "nazar"dır. Nazar; Arapça kökenli olup bakış anlamına gelse de Türkçede bu anlamına ek olarak kimi insanların bakışlarındaki zararlı güç ve bu nitelikleriyle, bir kişiye, hayvana veya nesneye bakmakla, canlı üzerinde hastalık, sakatlık, ölüm, nesne üzerinde düşme, kırılma, bozulma gibi olumsuz bir etkinin meydana gelmesi anlamını kazanmıştır (Boratav, 2013: 119). Nazar Türk kültüründe oldukça önemli bir yere sahiptir ve halk arasında nazar, nazardan korunma ve nazarın tedavisi ile ilgili birçok inanç mevcuttur. Gelincik kesme uygulaması da bu inanmalardan biridir.

Folklorik unsurlardan biri de uygulama sırasında bıçağın yani demirin kullanılmış olmasıdır. Demir, Türk inanç, gelenek ve edebiyatında kendisine oldukça geniş yer bulmuştur. Örnek olarak; yeni doğum yapan lohusaların yastığının altına alkarısı basmasını önlemek amacıyla bıçak veya makas konulması, ölen birinin karnına bıçak konulması, en bilinen Türk destanlarından biri olan Ergenekon Destanında demir dağın Türkleri 
koruyup saklamasından sonra dağı eritip yeni devletin kurulması vb. verilebilir (Türkmen ve Türker, 2014: 7). Demir, güç sembolü olmasının yanı sıra aynı zamanda koruyucudur. Hastalıklardan, ölüm ve büyülerden, tabiî afetlerden korunmada doğum, evlenme ve ölüm olaylarının içinde, halk hekimliğinde hep demirden yararlanılmıştır (Acıpayamlı'dan aktaran Türkmen-Türker, 2014: 7'den). Bu çalışmada bahsi geçen "gelincik kesme" uygulamasındaki bıçağın da nazarın etkilerinden kurtulmak ve nazardan korunmak amacıyla kullanıldığı sonucuna varılabilir.

Tedavi sırasında gerçekleșen bazı uygulamaların kökeni İslamiyet öncesi Şamanist döneme, bazısı ise İslami döneme aittir. Bunların bir kısmı ise kaynağını Şamanizm'den almakla birlikte İslamî renge bürünmüştür. Şamanların başlıca görevi, toplumun fiziki ve manevi sağlığını koruma ve kollama görevini gerçekleştirebilmesi için ruhlardan yetki alması ve bu ruhlarla iyi geçinmesidir (Bayat, 2015: 100). Ruhlar tarafından yetkilendirilen şaman, otama işlemini onların adına gerçekleştirir. "Gelincik kesme" uygulamasında karşımıza çıkan ise Şamanizm'deki inanca benzese de buradaki yetkilendirmenin İslamiyet'in etkisiyle Hazreti Fatıma tarafından verildiği kabul edilmektedir. Hatta Doğu Türkistan'ın "Müslüman" kamlarının kendi mesleklerinin piri olarak Hz. Fatıma'yı gördükleri bilinmektedir (İnan, 2015: 73). Ocaklının uygulama sırasında kendisinin değil de Hz. Fatıma'nın tedaviyi gerçekleştirdiğini söylemesi, Hz Fatıma'yı kendisine pir olarak kabul ettiğinin göstergesidir.

"Gelincik kesme" işlemine başlarken hasta olarak nitelenen nazarlı kişinin oturma şekli düşünüldüğünde (sağ ayağını uzatıp sol ayağının üzerine ve yüzü kıbleye bakacak şekilde) tedaviye İslami unsurların etkisi görülmektedir. Sağ ayağın kıbleye doğru uzatılarak oturulması dini anlamda "sağ"ın olumlu yönlerinden kaynaklanmaktadır. Dünya dilleri de dâhil olmak üzere sağ ve sol kavramları incelendiğinde genellikle "sağ"a olumlu bir anlam "sol"a ise daha olumsuz bir anlam yüklendiği dikkati çekmektedir. Sağa ve sola atfedilen bu tip inançların oluşmasında kültür ile sıkı bir bağı olan dini inanç sistemlerinin de etkili olabileceği düşünülebilir (Gülbetekin, 2015: 1280). Aça ise sol el konusunda oluşan bu olumsuz tabunun dini inançlara ek olarak "kirlilik" ve "normaldışılık" algısından kaynaklandığını ifade etmektedir (Aça, 2017: 210).

Tedavi sırasında çok defa kullanılan "üç" sayısının da Türk kültüründe çok önemli yeri vardır. Halk kültüründe ve edebiyatında en çok kullanılan sayının üç olduğu bilinmektedir. Bayram, üç sayısının büyüsüne ilişkin tarih boyunca dinlerin ve kültürlerin yaptığı vurguyu bireylerin de benimsediğini belirtir. Masal, edebiyat ve folklor gibi birçok alana da nüfuz eden bu anlayışın zamanla refleks haline dönüșerek insan düşünce ve davranışlarının ayrılmaz bir parçası haline dönüştüğünü ve üçü çağrıştırmayan ifade, tanım ya da eylemlerin adeta eksik kabul edildiğini belirtir (Bayram, 2019: 1315). Türk mitolojik sistemine göre evrenin üç kısımdan oluşması, üçler, yediler, kırklar inancı, gökten üç elma düşmesi, 
masallarda üçüncü kız veya erkek evladın şanslı olması, günün sabah-öğleakşam olmak üzere üç ana bölümden oluşması gibi birçok örnek üç sayısının kullanım yerlerinden birkaçını göstermektedir (Schimmel: 2000). Örneklerden de anlaşılacağı üzere üç sayısı hem İslamiyet öncesi Şamanizm inancında hem de İslami döneme ait inanışlarda kendisine yer edinmiştir.

\section{Sonuç}

Bu çalışmada nazardan kaynaklı olarak genellikle kadınlarda görülen ve "gelincik" şeklinde tabir edilen hastalığın tedavisi bir halk hekimliği örneği olarak ele alınmıştır. Tedavinin uygulanış sürecinde Şamanist ve İslami unsurların iç içe yer aldığı görülmüştür. Gelincik kesme işleminin yapılması sırasında halkbilimi açısından değer taşıyan birçok motife rastlanmaktadır. Anadolu halk hekimliğinde tedavi eden ocaklının yetişmesinde iki farklı yöntem ön plana çıkmaktadır. Bunlardan ilki ailedeki bir ocaklıdan kaynaklanan tedavi etme gücünün kan bağıyla yeni nesillere aktarılması, ikincisi ise usta-çırak ilişkisine benzer şekilde, ocaklının güvendiği bir bireye "el verme"sidir. Bu çalışmadaki ocaklının yetişme şekli ikinci yöntemde anlatılan "el verme-el alma" şeklinde olmuştur. Tedavide karşılaşılan ikinci bir folklorik unsur da hastalığın sebebinin nazar olmasıdır. Nazar inancı, etrafında oluşan maddi (nazar boncuğu, sarımsak, iğde dalı vb.) ve manevi (tedavisi, nazarı değen kişiler vb.) kültürel değerler nedeniyle halk bilimi açısından önemlidir. Yöre insanı (Düzce ili) nazara inanmakla birlikte gelincik olarak adlandırılan hastalığın sebebinin de nazardan kaynaklandığını düşünmektedir. İyileştirme sırasında ocaklının kendi gücünün yanı sıra halk hekimliğinde pir olarak kabul edilen $\mathrm{Hz}$. Fatıma'nın yardımını da almak amacıyla "El benim elim değil Fatma Anamızın elidir, şifa ondandır" şeklindeki sözleri de tedavideki İslamî ve folklorik bir unsur olarak dikkati çekmektedir. Gelincik kesme uygulamasında karşılaşılan bir diğer motif, Türk kültüründe iyileştirici özelliği bulunan demirin gücünden yararlanılmasıdır. Hasta olan kişinin tüm vücudunda demir gezdirilmesiyle kişinin hastalıktan arındırılmasını hedeflenmektedir. Türklerdeki önemli sayılardan biri olan 3 sayısının tedavide birçok yerde tekrar edilmesi, bütün dünyada "sol" üzerinde oluşan tabudan kaynaklı olarak sol ayağın üstüne oturup sağ ayağın kıbleye doğru uzatılması da rastlanan motiflerdendir. Halk bilimi açısından değer taşıyan birçok unsuru barındıran gelincik kesme uygulamasının kayıt altına alınması, kültürel varlığın korunması ve sonraki nesillere aktarılması için önemlidir.

\section{KAYNAKÇA}

\section{Yazılı Kaynaklar}

Acıpayamlı, O. (1961). Türkiye'de doğumla ilgili âdet ve inanmaların etnoljik etüdü. Erzurum: Atatürk Üniversitesi.

Acıpayamlı, O. (1969). Türkiye folklorunda halk hekimliği ve özellikleri. Dil Tarih Coğrafya Fakültesi Dergisi, XXVI: 1-9. 
Aça, M. (2017). Kültür ve dayatma: Türk kültüründe sol el tabusu. International Conference: The West of The East, The East of The West Proceedings, Prague/Czechia, 205-212.

Bayat, A. H. (2016). Tıp tarihi. İstanbul: Pınarbaş Matbaacılık.

Bayat, F. (2015). Türk kültüründe kadın şaman. İstanbul: Ötüken Neşriyat.

Bayram, S. (2019). Tarihten günümüze üçün sembolizmi: İnsan düşünce ve eylemlerinin üçle ilişkisi. Uluslararası Sosyal Araştırmalar Dergisi, 12 (65), 1315-1325.

Başaran, U. - Solmaz, S. (2015). Halk hekimliğinin dünü ve bugününe dair iki farklı uygulamadan hareketle geleneksel-modern tıp karşılaştırması denemesi. II. Uluslararası Genç Halk Bilimciler Sempozyumu Bildirileri, (Ed.: Metin Özarslan), 59-69, Ankara: Hacettepe Üniversitesi.

Boratav, P. N. (2013). 100 soruda Türk folkloru. Ankara: BilgeSu.

Çelik, A. (2018). Türk toplumunun sözel belleğindeki al karısı tasarımları üzerine. Doğaüstü Varlıklar ve Anlatılar Üzerine Íncelemeler. (Ed.: Altuğ Ortakcı), Ankara: Kesit.

Doğan, Ş. (2011). XIV.-XV. yüzyll Türkçe tıp metinlerinde halk hekimliği izleri. Millî Folklor, 23 (89), 120-132.

Duvarcı, A. (1990). Halk hekimliğinde ocaklar. Millî Folklor, 2 (7), 33-38.

Ekici, M. (2015). Halk bilgisi (folklor) derleme ve inceleme yöntemleri. Ankara: Geleneksel.

Gülbetekin, E. (2015). Sağ=sol? 'sağ-sol' kavramları ve beyin asimetrisi. International Journal of Human Sciences, 12-(2), 1279-1295.

Hufford, D. J. (2009). Halk hekimleri. (Çev.: Mustafa Sever). Halkbiliminde Kuramlar ve Yaklaşımlar 3, 382-390, Ankara: Geleneksel.

İnan, A. (2015). Tarihte ve bugün Şamanizm. Ankara: Türk Tarih Kurumu.

Malinowski, B. (1990). Büyü, bilim ve din, (Çev.: Saadet Özkal), İstanbul: Kabalcı.

Ronan, C. A. (2005). Bilim tarihi. (Çev.: E. İhsanoğlu. - F. Günergur), Ankara: TÜBİTAK.

Schimmel, A. (2000). Sayıların gizemi. (Çev.: Mustafa Küpüşoğlu), İstanbul: Kabalcı.

Sever, M. (2015). Halk tıbbı, halk hekimliği. Gazi Akademik Bakış, 9 (17), 181-192.

Şar, S. (2005). Anadolu'da halk hekimliği uygulamaları. Türkiye Klinikleri Journal of Medical Ethics, 13 (2), 131-136.

Türkmen, F. - Ferah T. (2014). Geleneklerde ve inançlarda demir. Türk Dünyası Incelemeleri Dergisi, 14 (1), 1-8.

\section{Sözlü Kaynaklar}

KK-1 : Şaziye Demir, Yaş: 68. Eğitim: ilkokul 2. Sınıf, Düzce. (Görüşme Tarihi: 26.10.2017) 